\title{
Protein and Phenolic Contents and Antioxidant Activities of 14 Early Maturing Potatoes as Affected by Processing
}

\author{
Reena Grittle Pinhero1, Rong Tsao², Qiang Liu², James Alan Sullivan³, Benoit Bizimungu", \\ Rickey Y. Yada1,5 \\ ${ }^{1}$ Department of Food Science, University of Guelph, Guelph, Canada \\ ${ }^{2}$ Agriculture and Agri-Food Canada, Guelph Food Research Centre, Guelph, Canada \\ ${ }^{3}$ Department of Plant Agriculture, University of Guelph, Guelph, Canada \\ ${ }^{4}$ Agriculture and Agri-Food Canada, Fredericton, Canada \\ ${ }^{5}$ Faculty of Land and Food Systems, University of British Columbia, Vancouver, Canada \\ Email: rpinhero@uoguelph.ca
}

Received 2 December 2015; accepted 18 January 2016; published 21 January 2016

Copyright (C) 2016 by authors and Scientific Research Publishing Inc.

This work is licensed under the Creative Commons Attribution International License (CC BY).

http://creativecommons.org/licenses/by/4.0/

(c) (i) Open Access

\section{Abstract}

The effects of processing and genotype (fourteen early potato varieties) were evaluated for their phytochemicals, total phenolics (TPC), total flavonoids (TFC), total anthocyanins (TAC), antioxidant activities measured by ORAC, FRAP and DPPH assays and protein content. While all these profiles were highly dependent on the potato variety and processing, F09085, F10090, French Fingerlings, Purple Fiesta, Red Thumb, Ciklamen and Norland were identified as nutritionally rich in phytochemicals such as TPC, TFC, TAC, higher antioxidant capacities and protein $(p<0.05)$. In general, TPC, TFC and TAC increased after processing and were highest in the retrograded samples as compared to the raw samples, whereas protein contents decreased following processing $(p<$ 0.05). Significant and positive correlations were observed between TPC, TAC, TFC, FRAP, ORAC and DPPH assays $\left(R^{2}, 0.63,0.83,0.88,0.87,0.69\right.$ for uncooked, $0.48,0.84,0.76,0.89,0.79$ cooked and $0.40,0.87,0.88,0.60,0.68$ retrograded samples, respectively, $p<0.0001$ ).

\section{Keywords}

Potato, Phenolic Content, Anthocyanins, Antioxidant Potential, Protein

\section{Introduction}

Potato (Solanum tuberosum L.) ranks third behind rice and wheat in terms of world food production as food 
energy source and is the world's number one non-grain food commodity [1]. Potatoes are a valuable dietary food due to their diverse functional ingredients including protein, fiber, vitamins, and phytochemicals such as polyphenols [1] [2]. Plant polyphenols including phenolic acids, flavonoids, anthocyanins and other secondary metabolites are natural antioxidants that play a role in the treatment and prevention of cancers, cardiovascular diseases, neurodegenerative diseases and diabetes [3] [4]. There has been great interest in identifying potato varieties rich in antioxidant phytochemicals for the above-mentioned potential health benefits. The content of polyphenols in potatoes appears to be cultivar dependent [2] [5]. A study involving 74 Andean potato cultivars has reported an approximate 11-fold variation in total phenolic content and a high correlation between polyphenol content and antioxidant activities [2]. Although potatoes are known as a high energy carbohydrate source, they also contain good quality protein. Potato protein is nutritionally comparable to whole egg protein and contains higher content of lysine compared to other vegetable protein from pea and cereals [6]. Potato proteins comprise about $50 \%$ protease inhibitors, $40 \%$ patatin and the rest are high molecular weight proteins [7]. Patatin is a glycoprotein which is a storage protein that also exhibits cultivar-dependent antioxidant activity [8]. Studies involving 32 potato genotypes have shown extensive variations in protein quality and quantity [9]-[11].

Various factors such as genotype, growing conditions, storage, maturity, color of the flesh and skin and processing conditions can affect the content of phytochemicals and protein in potatoes [11]-[13]. Many studies have identified high anthocyanin content in colored potatoes, and have reported varying levels of phenolic and flavonoid contents in different varieties [14] [15]. The presence and absence of anthocyanins are regulated by a dominant gene which controls the pigmentation. Genotype by location differences are observed in the contents of anthocyanin, phytochemicals and total antioxidant activities [15]. Potatoes are also now emerging as an important food crop in many parts of the world which has not traditionally consumed potatoes as a dietary staple, e.g., India and China [16]. Hence nutritional improvements of potatoes for health benefits as well as identifying varieties high in phytochemicals and proteins would likely have a great impact on global health and well-being. There are also conflicting reports of either decrease or increase in the phytochemicals content and their antioxidant activities after various processing methods [13] [14]. Despite many of the studies on phytonutrient content of potatoes [5] [13]-[15], literature is lacking on the effect of processing on phenolic and protein contents as well as antioxidant activities of early maturing potatoes. Early maturing new potatoes have higher amounts of some phytonutrients, including folate [17] than mature potatoes and are often eaten with skin on which will contribute to higher fiber content. Besides, identifying high nutrient early potatoes which can be used in many culinary purposes, will appeal to the health-conscious consumers. Hence, the present study evaluated fourteen early maturing white, yellow, red and purple potato varieties that are adapted to Ontario growing conditions and the effect of processing on their phytochemicals and protein contents as well as antioxidant activities.

\section{Materials and Methods}

\subsection{Potato Sample}

A total of 14 potato varieties were tested in this study. Eleven early maturing potato varieties (Adora, bright yellow flesh, lightly netted buff skin; Yellow Star, yellow skin and flesh; Carling Ford, white; Chaleur, white; Dakota Pearl, cream flesh, light yellow skin; Purple Fiesta, dark purple skin and flesh; French Fingerlings, rose pink skin, creamy yellow flesh with some splashes of pink; Ciklamen, red skin and creamy flesh; Red Thumb, red skin and flesh; Maris Peer, creamy flesh and skin; and smart, yellow skin, medium to dark yellow flesh were collected from Grand Bend Produce, 10026 Walker Road, Grand Bend, Ontario. Two advanced potato selections from Agriculture and Agri-Food Canada, F09085 (deep reddish purple flesh and skin), F10090 (deep reddish purple flesh and skin) and Norland (red skin and creamy yellow flesh) were grown at Elora Research Station, University of Guelph, Ontario. These varieties were selected as they are currently available, adapted to Ontario growing conditions, and could be a healthier choice for consumers. The color range was chosen to suit consumer preferences. The potatoes were grown under normal commercially accepted management practices. Fields were irrigated as needed and standard fertilizer practices were followed based on soil test results. Pre-planting soil tests of Conestoga silt loam soil type reported organic matter $2.9 \%$ and cation exchange of 17.2 MEQ/100g. The soil $\mathrm{pH}$ was 7.7. The field had previously been in barley, fall killed, deep plowed, spring disced and cultivated before planting. Plots were fertilized at the rate of $130 \mathrm{~kg} \mathrm{~N}, 180 \mathrm{~kg} \mathrm{P}$ and $190 \mathrm{~kg} \mathrm{~K}$ per hectare based on soil data recommendation. Initially $46 \mathrm{~kg} P$ and $60 \mathrm{~kg} \mathrm{~K}$ were broadcasted followed by the balance of fertilizers applied at planting time. All potatoes were washed and used for analyses as (1) fresh (uncooked), (2) 
after boiling (cooked) and (3) boiled and cooled for 48 hrs at $4^{\circ} \mathrm{C}$ (retrograded).

\subsection{Sample Preparation}

Uncooked samples were prepared by gently washing potatoes along with the skin and cutting into small strips $(27 \mathrm{~mm} \times 4 \mathrm{~mm}, \mathrm{LxW})$ using a vegetable grater and frozen immediately. Cooked samples were prepared by cutting potatoes (with the skin) into four quarters, boiling for 10 minutes in water (until the sample could be pierced through using a fork), and then slicing them into thin pieces using a knife. One set of these cooked samples was refrigerated at $4^{\circ} \mathrm{C}$ for $48 \mathrm{hrs}$, to produce retrograded samples. One-hundred grams of each of uncooked, cooked, and retrograded samples were freeze dried using VIRTIS freeze drier (The Virtis Company, Gardiner, New York 12525). The freeze dried samples were ground using a coffee grinder, passed through a $250 \mu \mathrm{m}$ sieve, and kept in air-tight plastic bags at room temperature for two days before use for various analyses.

\subsection{Total Polyphenol Content Analysis}

Samples for total polyphenol content (TPC) was extracted using $80 \%$ methanol following a reported protocol [18]. Briefly, dried potato powder ( $0.5 \mathrm{~g}$ ) was extracted in $4 \mathrm{ml}$ of $80 \%$ methanol for $12 \mathrm{~h}$ with continuous shaking at $200 \mathrm{rpm}$ initially. The extract was centrifuged in a bench top centrifuge $\left(4^{\circ} \mathrm{C}\right)$ at $4500 \mathrm{~g}$ for $10 \mathrm{~min}$ and the supernatant was then collected. The residue was re-extracted for additional $2 \mathrm{~h}$ and the pooled supernatant was stored at $-30^{\circ} \mathrm{C}$ until use. Total polyphenol contents was determined using the Folin-Ciocalteu colorimetric method [19] using BioTek Synergy H4 hybrid reader (Fisher Scientific, Markham, Ontario, Canada). Ten microliters of standards (chlorogenic acid), blank or samples were loaded into a 96 well microplate followed by $95 \mu \mathrm{l}$ of Folin-Ciocalteu reagent and allowed to stand at room temperature for $5 \mathrm{~min}$. Ninety-five $\mu \mathrm{l}$ sodium carbonate solution (6\%) was added and allowed to react at $40^{\circ} \mathrm{C}$ in the dark for $30 \mathrm{~min}$, and the absorbance was read at $725 \mathrm{~nm}$. Samples were loaded in triplicates and the average measurement was taken and expressed as $\mathrm{mg}$ chlorogenic acid equivalents (CAE) per gram of dry weight. The experiment was repeated at least three times.

\subsection{Determination of Total Flavonoid Content}

The total flavonoid content (TFC) was determined based on the method of Zou [20]. A $25 \mu$ laliquot of appropriately diluted samples or catechin standard dilutions (0, 15.6, 31.25, 62.5, 125, 250 and $500 \mathrm{mg} / \mathrm{L}$ ) was mixed with $110 \mu \mathrm{l}$ of $0.066 \mathrm{M} \mathrm{NaNO}_{2}$ solution in a 96 well-plate. After incubating for $5 \mathrm{~min}, 15 \mu \mathrm{l}$ of $0.75 \mathrm{M}$ aluminum chloride solution were added and allowed to react for another $6 \mathrm{~min}$ at room temperature followed by the addition of $100 \mu \mathrm{l}$ of $0.5 \mathrm{M} \mathrm{NaOH}$. The absorbance was read at $510 \mathrm{~nm}$ using BioTek SynergyH4 hybrid reader (Fisher Scientific, Markham, Ontario, Canada) and the total flavonoid content was determined from the standard curve and expressed as mg of $(+)$ catechin equivalent (CE) per gram of dry weight.

\subsection{Determination of Total Anthocyanin Content}

Anthocyanin was extracted twice from $1 \mathrm{~g}$ of potato dry matter in $10 \mathrm{ml}$ of methanol: water: acetic acid (80:19:1, $\mathrm{v} / \mathrm{v} / \mathrm{v}$ ) in a $15 \mathrm{ml}$ screw-capped plastic tube after vortexing and placing in a rotary shaker for 2 hrs. The supernatant was pooled after centrifuging for 10 mins at $3000 \mathrm{~g}$ and concentrated using a rotary evaporater at $35^{\circ} \mathrm{C}$ to dryness and stored at $-30^{\circ} \mathrm{C}$ until use. Total anthocyanin content was determined based on the $\mathrm{pH}$ differential method [21]. Twenty-five $\mu \mathrm{l}$ of the standards or samples were mixed in separate wells of a 96-well plate, one with $250 \mu \mathrm{l}$ of $\mathrm{pH} 1.0$ buffer $(0.1 \mathrm{M} \mathrm{HCl} / 4.9 \mathrm{mM} \mathrm{KCl})$ and the other with $250 \mu \mathrm{l}$ of pH 4.5 buffer $(24.8 \mathrm{mM}$ $\mathrm{NaOAc}$ ). Absorbance was read at 535 and $700 \mathrm{~nm}$ using BioTek SynergyH4 hybrid reader (Fisher Scientific, Markham, Ontario, Canada). The net absorbance (A) for the cyanidin chloride standard and the samples were calculated using $\mathrm{A}=[(\mathrm{A} 535-\mathrm{A} 700) \mathrm{pH} 1.0-(\mathrm{A} 535-\mathrm{A} 700) \mathrm{pH} 4.5]$. The concentration of the anthocyanin was calculated using the linear equation and expressed as mg cyanidin chloride equivalent (CCE) per gram dry weight of potato samples. The mean value was obtained from two separate experiments each consisting of four replications.

\subsection{2, 2-Diphenyl-1-picrylhydrazyl (DPPH) Radical Scavenging Capacity Assay}

The DPPH radical scavenging capacity assay was based on the method of Yamaguchi et al. [22]. The 96 well 
microplate was loaded with $25 \mu \mathrm{l}$ of either potato extracts or standard (Trolox) followed by $175 \mu \mathrm{l}$ of $152.15 \mu \mathrm{M}$ DPPH solution prepared in methanol. The absorbance was read at $515 \mathrm{~nm}$ at room temperature after 40 minutes incubation using BioTek SynergyH4 hybrid reader (Fisher Scientific, Markham, Ontario, Canada). The DPPH antioxidant activity was expressed as mg of trolox equivalents (TE) per gram dry weight.

\subsection{Ferric Reducing Antioxidant Power (FRAP) Assay}

FRAP assay was performed according to the methods of Benzie and Strain (1996) and Tsao, Yang, Xie, Sockovie and Khanizadeh [23] [24]. Ten $\mu \mathrm{l}$ of sample or standard was mixed in the wells of a 96-well plate with 300 $\mu \mathrm{l}$ of freshly prepared FRAP reagent. The FRAP reagent was prepared by mixing $300 \mathrm{mM}$ acetate buffer, $\mathrm{pH}$ 3.6, $10 \mathrm{mM}$ 2,4,6-tripyridyl-S-triazine (TPTZ) and $20 \mathrm{mM} \mathrm{FeCl3} \mathrm{mixed} \mathrm{at} \mathrm{10:1:1} \mathrm{(v/v/v).} \mathrm{The} \mathrm{plate} \mathrm{was} \mathrm{incubated} \mathrm{at}$ room temperature for $2 \mathrm{~h}$ and the absorbance was read at $593 \mathrm{~nm}$ using BioTek SynergyH4 hybrid reader (Fisher Scientific, Markham, Ontario, Canada). The final FRAP value was calculated on the basis of $100 \mu \mathrm{M}$ ascorbic acid being equivalent to a $200 \mu \mathrm{M}$ FRAP value and expressed as $\mu \mathrm{mol}$ ascorbic acid equivalent (AAE) per gram dry weight.

\subsection{Oxygen Radical Absorption Capacity (ORAC)}

The oxygen radical absorption capacity was used to measure the antioxidant capacity [25]. Twenty-five microliters of the 100-fold diluted sample extracts or standard were mixed with $150 \mu \mathrm{l}$ of fluorescein working solution $\left(8.68 \times 10^{-5} \mathrm{mM}\right)$ in wells of a 96-well plate. The plate was equilibrated for $30 \mathrm{~min}$ at $37^{\circ} \mathrm{C}$ in a BioTek SynergyH4 hybrid reader (Fisher Scientific, Markham, Ontario, Canada). Reaction was initiated by the addition of 25 $\mu \mathrm{l}$ of a free radical generator AAPH (2, 2'-azobis(2-aminopropane)dihydrochloride, $153 \mathrm{mM}$ ) solution and shaking at maximum intensity for $10 \mathrm{~s}$ in the plate reader. The multi-detection microplate reader recorded the fluorescence kinetically every minute for $2 \mathrm{~h}$ with excitation and emission set at $485 \mathrm{~nm}$ and $520 \mathrm{~nm}$ respectively. A standard curve was prepared with trolox concentrations ranging from 6.25 to $100 \mu \mathrm{M}$. The ORAC values were calculated as the area under the curve (AUC) and expressed as $\mu$ moles of trolox equivalent (TE) per gram dry weight of potato dry matter. The experiment was repeated twice with eight replicates per sample.

\subsection{Total Protein Determination}

Total protein was extracted from $150 \mathrm{mg}$ of freeze-dried potato in $1.5 \mathrm{ml}$ of $62.5 \mathrm{mM}$ Tris-HCl buffer, $\mathrm{pH}$ 6.8, with $2 \%$ SDS by vortexing at 15 minutes intervals for about $4 \mathrm{~h}$ at $4{ }^{\circ} \mathrm{C}$ and centrifuging at $8161 \mathrm{~g}$ for $5 \mathrm{~min}$ [26]. The supernatant was collected and stored at $-30^{\circ} \mathrm{C}$ until use. Protein content was determined using the microplate assay of DCTM protein determination (Bio-Rad Protein Assay Kit). The experiment was replicated twice with at least eight determinations for each experiment.

\subsection{Data Analyses}

Data analysis was carried out using GraphPad Prism 6 Software (GraphPad Software Inc., California, USA). Differences among the various treatments were carried out using one-way analysis of variance (ANOVA) and Tukey's multiple comparison test was used to compare the means $(p \leq 0.05)$. Pearson correlation was also used to establish a relationship between TPC, TFC, TAC, and FRAP, ORAC and DPPH assays.

\section{Results}

\subsection{Total Phenolic Contents (TPC)}

Significant differences were noted in TPC among varieties and after processing (Figure $1, p \leq 0.05$ ). TPC was analyzed using chlorogenic acid as standard. In general, highest TPC was observed in retrograded potato samples followed by boiled and uncooked samples. F09085, F10090, Red Thumb, Purple Fiesta and French Fingerlings were the varieties which registered the highest TPC in uncooked, boiled and retrograded samples (Figure 1). Among the varieties, the highest TPC were obtained in selections F09085 (10.35 mg CAE/g) and F10090 (8.47 mg CAE/g), Red Thumb (8.42 mg CAE/g), Purple Fiesta (6.58 mg CAE/g), and French Fingerlings (5.04 mg CAE/g) after retrogradation (Figure 1). 


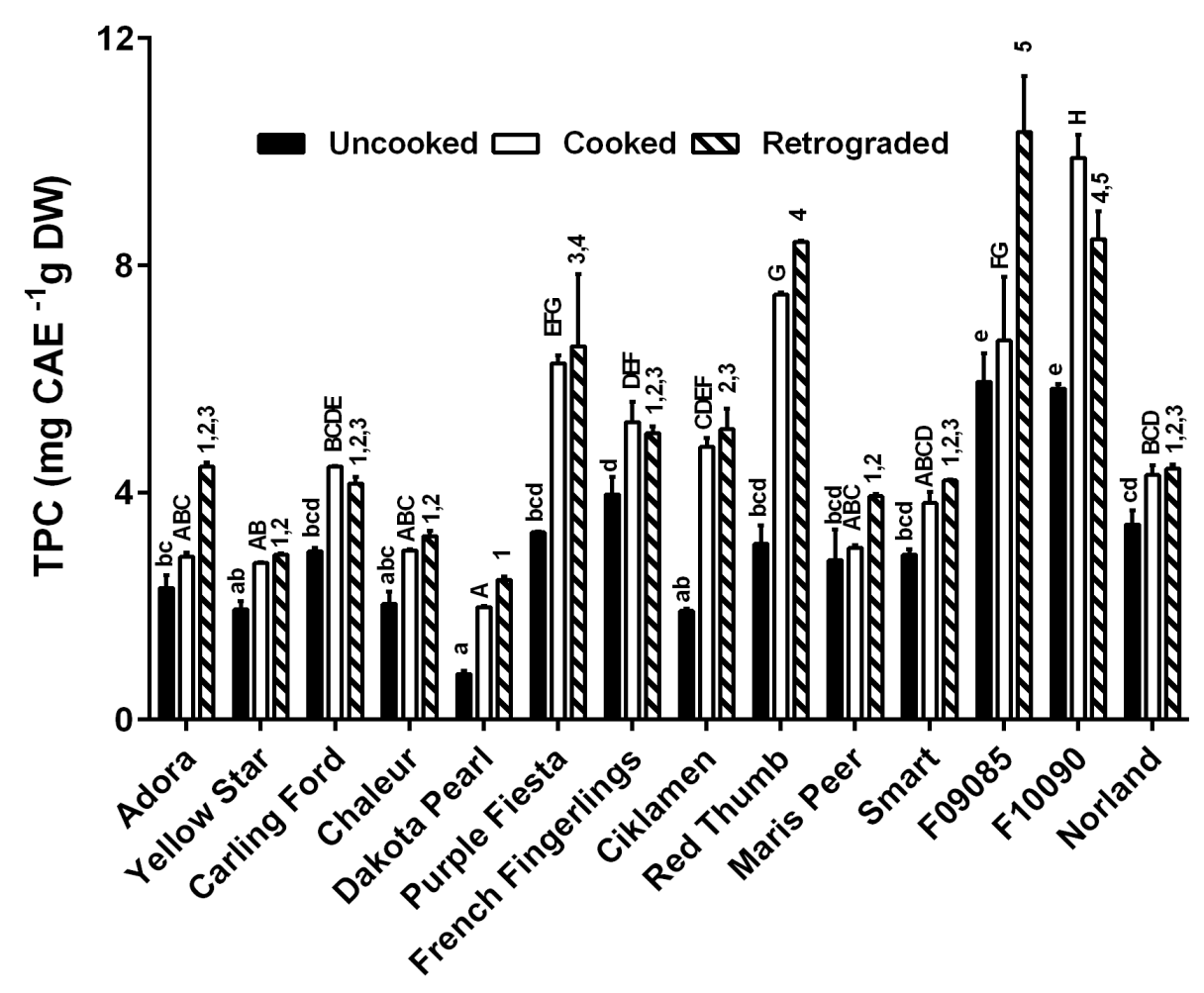

Potato varieties

Figure 1. Effect of variety and processing on mean total phenolic contents (TPC) of potatoes as measured on chlorogenic acid equivalents. Each bar represent mean of 8 values, from four replicates and two determination per replicate along with standard error. Bars with different letters of a, A, 1 denote significant differences between uncooked, cooked and retrograded samples, respectively (Tukey's test, $p \leq 0.05$ ).

\subsection{Total Flavonoid Content (TFC)}

TFC varied significantly among varieties and with all processing methods (Figure 2, $p \leq 0.05$ ). Selection F10090 registered the highest TFC in all the processing methods with the highest content of $3.92 \mathrm{mg} \mathrm{CE} / \mathrm{g}$ in boiled samples (Figure 2). After F10090, selection F09085, varieties Purple Fiesta, Red Thumb, Norland, French Fingerlings and Ciklamen also had high TFC values. Similar to TPC, TFC was higher in the retrograded samples followed by boiled and uncooked samples.

\subsection{Total Anthocyanin Content (TAC)}

Anthocyanin contents were detected only in purple/red colored varieties such as Purple Fiesta, French Fingerlings, Ciklamen, Red Thumb, F09085, F10090 and Norland (Figure 3). TAC varied significantly among these varieties and after processing ( $p \leq 0.05$ ) with the highest contents in Purple Fiesta followed by F09085, F10090, Red Thumb, Ciklamen, French Fingerlings and Norland after boiling and retrogradation. Boiling and retrogradation increased the TAC in all these varieties with the exception of F09085 and F10090.

\subsection{Antioxidant Activities}

Antioxidant activities were determined using three chemical model assays, ORAC, FRAP and DPPH. Significant differences were observed among varieties in their antioxidant activities as measured by the three assays among all processing methods $(p \leq 0.05)$. In general, the antioxidant activity was highest in retrograded samples followed by boiled and uncooked potatoes. Among the uncooked potatoes, the highest ORAC values $(p \leq 0.05)$ were observed in F09085 and F10090 followed by French Fingerlings, Red Thumb, Purple Fiesta, Carling Ford and Norland (Figure 4). A similar trend was observed in the ORAC values of boiled and retrograded potatoes 


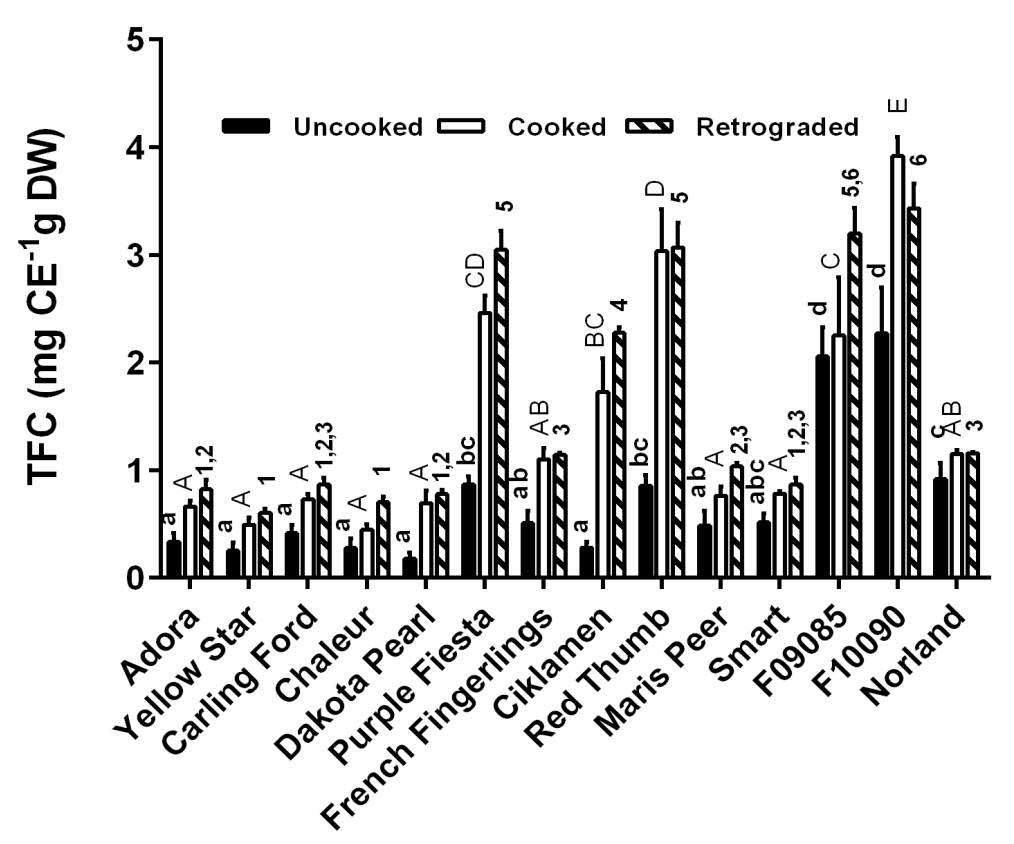

Potato varieties

Figure 2. Effect of variety and processing on mean total flavonoid contents (TFC) of potatoes as measured on catechin equivalents (CE). Each bar represent mean of 12 values, from 3 replicates and four determinations per replicate along with standard error. Bars with different letters of a, A, 1 denote significant differences between uncooked, cooked and retrograded samples, respectively (Tukey's test, $p \leq 0.05$ ).

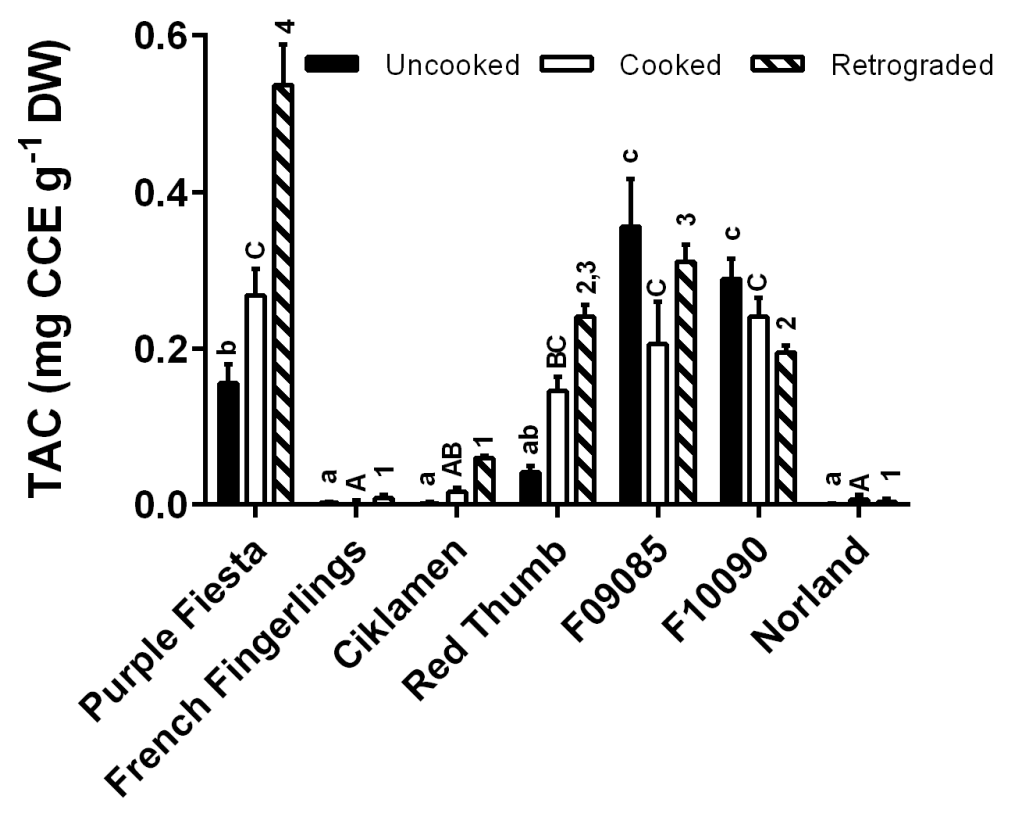

Potato varieties

Figure 3. Effect of variety and processing on mean total anthocyanin contents (TAC) of potatoes as measured on cyanidin chloride equivalents (CCE). Each bar represents mean of 10 values with two replicates and five determinations per replicate along with standard error. Bars with different letters of a, A, 1 denote significant differences between uncooked, cooked and retrograded samples, respectively (Tukey's test, $p \leq 0.05)$. 


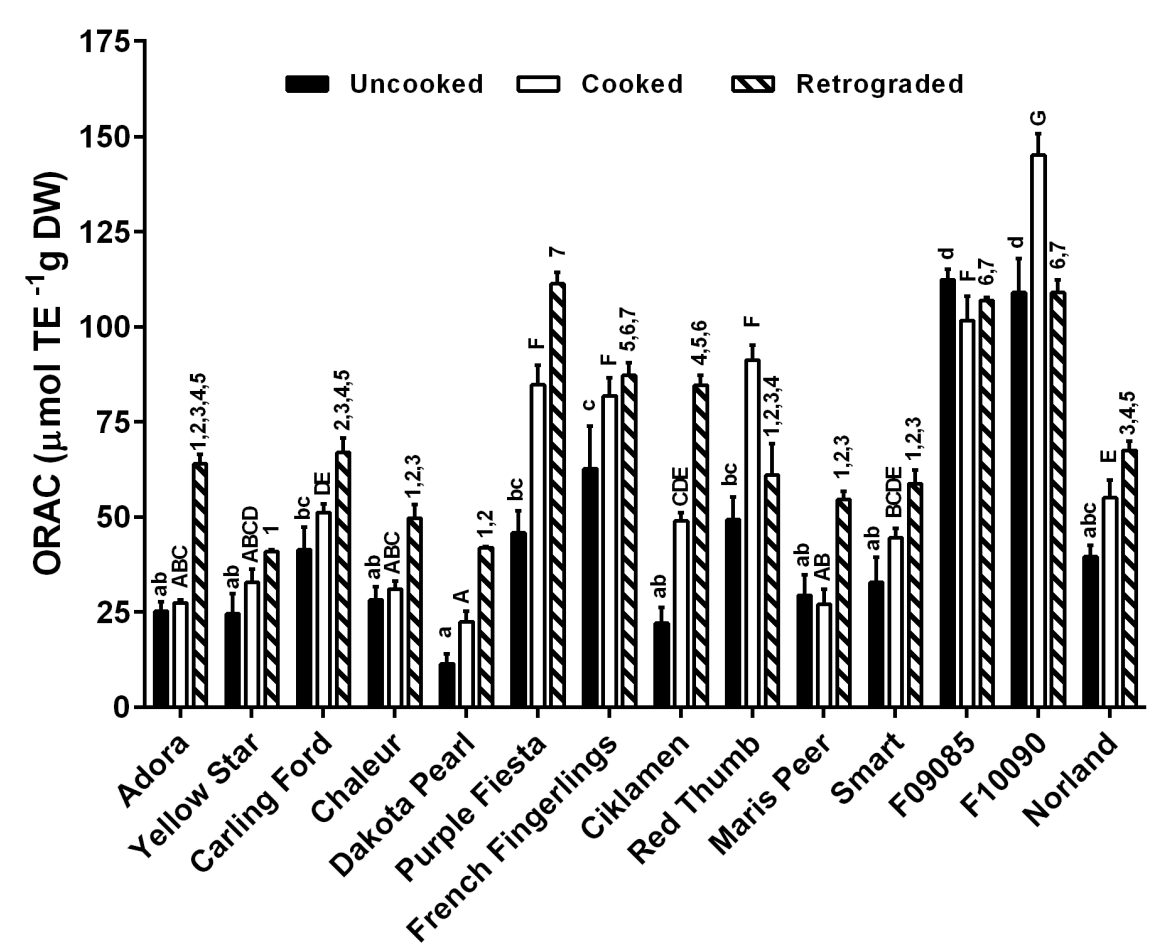

Potato varieties

Figure 4. Effect of variety and processing on antioxidant capacity as measured by ORAC on trolox (TE) equivalents. Each bar represents mean of16 values, from four replicates and four determinations per replicate and standard error. Bars with different letters of a, A, 1 denote significant differences between uncooked, cooked and retrograded samples, respectively (Tukey's test, $p \leq 0.05$ ).

with some exceptions. A range of almost 10-fold difference in ORAC values were observed between the highest F09085 and lowest Dakota Pearl in uncooked values whereas the gap decreased to 6-fold for boiled and 3-fold for retrograded samples. Processing as well as varietal differences also affected the FRAP values significantly (Figure 5, $p \leq 0.05$ ). F10090, F09085, Red Thumb, and Purple Fiesta registered the highest FRAP values in all the three categories of uncooked, boiled and retrograded potatoes $(p \leq 0.05)$. A range of 6 -fold, 13-fold and 3 -fold difference among the varieties between the lowest and highest FRAP values was observed in the uncooked, boiled and retrograded potatoes, respectively. The antioxidant activities of varieties as measured by DPPH, were also significantly different $(p \leq 0.05)$. F10090 registered the highest DPPH value both in uncooked and boiled samples whereas Red Thumb had the highest value in the retrograded samples (Figure 6). In general, DPPH antioxidant activities were highest in F10090, F09085, Red Thumb, Purple Fiesta, Norland, Ciklamen, French Fingerlings and Adora in all the uncooked, boiled and retrograded samples and the DPPH activities increased following boiling and retrogradation (Figure 6). The uncooked, boiled and retrograded samples showed a 31-, 6- and 4-fold differences, respectively, between the lowest and highest DPPH values.

\subsection{Protein Content}

Protein contents of the varieties differed significantly in all uncooked, boiled and retrograded samples $(p \leq 0.05)$. Protein content ranged from $5.7 \%$ to $9.0 \%$, $3.2 \%$ to $7.4 \%$ and $3.3 \%$ to $6.7 \%$ on dry weight basis in uncooked, boiled and retrograded potatoes, respectively (Figure 7). It should be noted that the protein content of uncooked samples was higher in all the varieties compared to boiled and retrograded potatoes. F09085 and French Fingerlings had the highest protein contents in uncooked samples followed by F10090, Dakota Pearl, Ciklamen, Yellow Star, Purple Fiesta and Red Thumb. The remainder of the varieties had similar protein contents in the uncooked samples. In the boiled and retrograded samples, F09085, F10090 and Red Thumb registered the highest protein contents. 


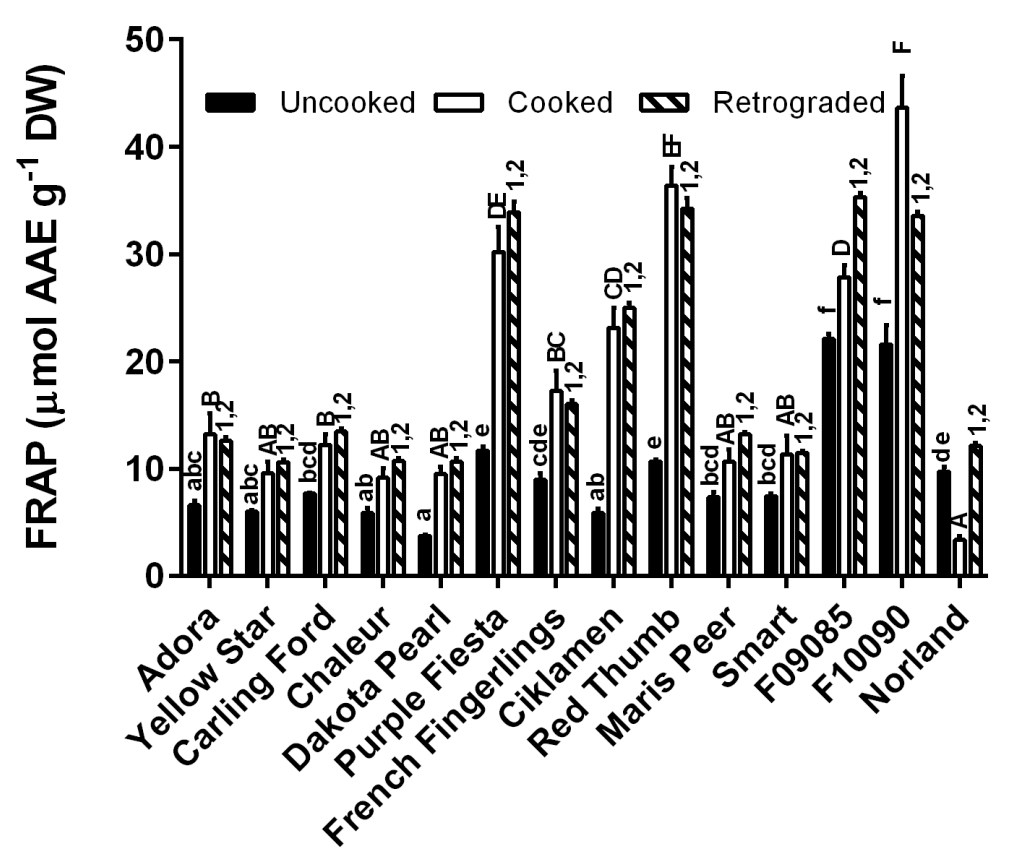

\section{Potato varieties}

Figure 5. Effect of variety and processing on antioxidant capacity as measured by FRAP on ascorbic acid (AAE) equivalents. Each bar represent mean from 12 values with four replicates and three determinations per replicate and standard error. Bars with different letters of a, A, 1 denote significant differences between uncooked, cooked and retrograded samples, respectively (Tukey’s test, $p \leq 0.05$ ).

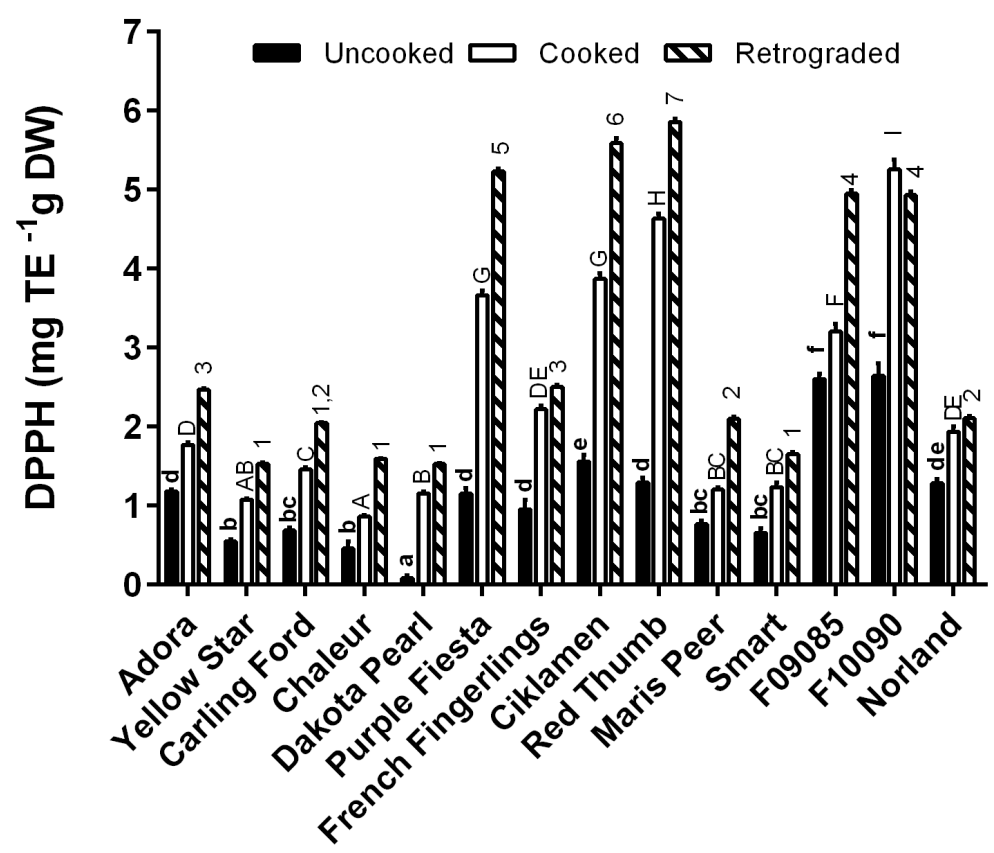

Potato varieties

Figure 6. Effect of variety and processing on antioxidant capacity as measured by DPPH on trolox (TE) equivalents. Each bar represents mean of 14 determinations and standard error. Bars with different letters of a, A, 1 denote significant differences between uncooked, cooked and retrograded samples, respectively (Tukey's test, $p \leq 0.05$ ). 


\subsection{Correlation of TPC, TFC, and TAC with Antioxidant Activities}

Significant positive correlations were observed between TPC, TAC, TFC and ORAC, FRAP and DPPH (Table 1). The correlations were high between the antioxidant activities measured by FRAP, ORAC and DPPH with TPC, TAC, TFC, and among FRAP, ORAC and DPPH in the uncooked samples. A similar trend was observed in cooked and retrograded samples with some exceptions. The correlation, even though significant, was not strong between TAC, FRAP, ORAC and DPPH in cooked potatoes. In retrograded samples, a strong correlation was not observed between TAC and ORAC, DPPH and TPC and TAC.

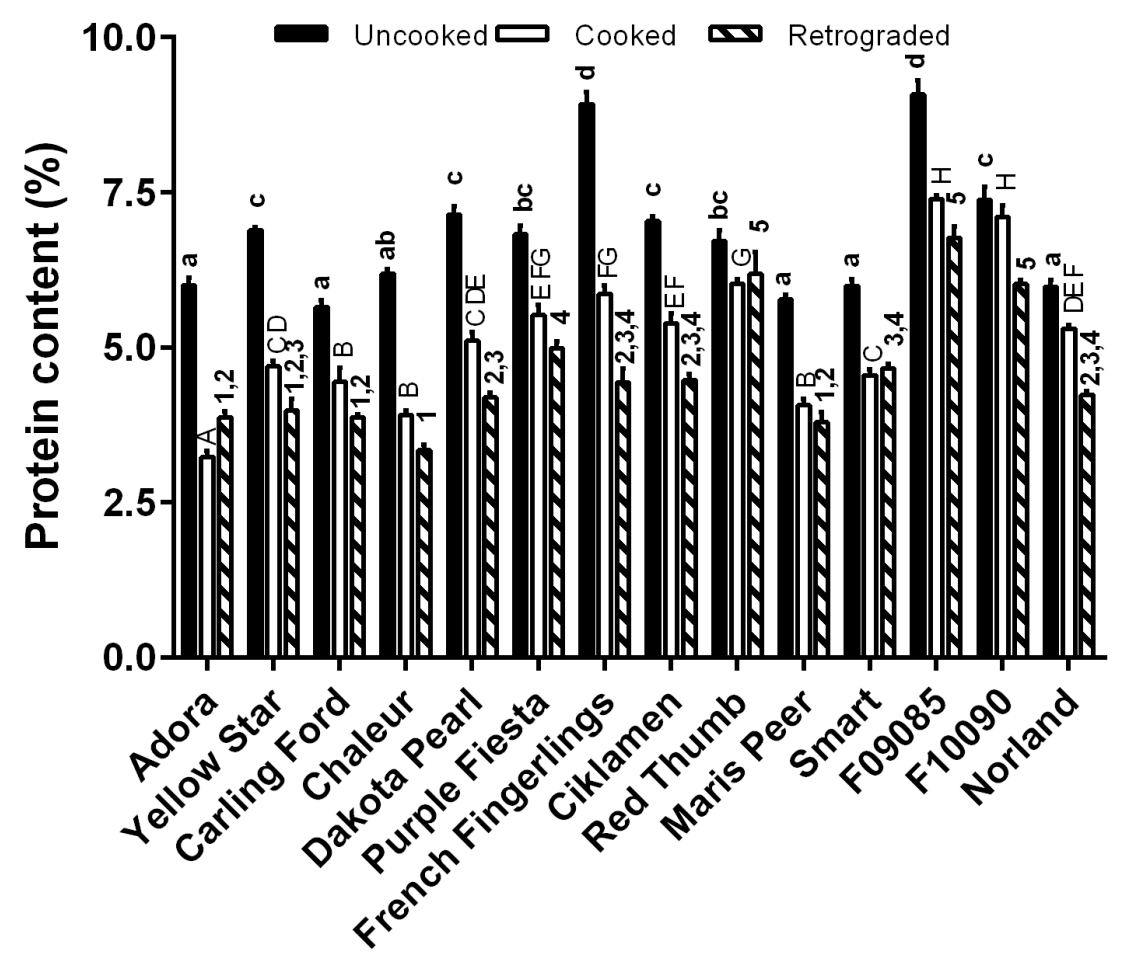

\section{Potato varieties}

Figure 7. Effect of variety and processing on total protein contents of potatoes. Each bar represents mean of 16 values from two replicates and eight determinations per replicate and standard error. Bars with different letters of a, A, 1 denote significant differences between uncooked, cooked and retrograded samples, respectively (Tukey's test, $p \leq 0.05$ ).

Table 1. Pearson correlations of bioactives $\left(\mathrm{R}^{2}\right)$ to antioxidant potential.

\begin{tabular}{|c|c|c|c|c|c|c|c|c|c|c|c|c|c|c|c|}
\hline & \multicolumn{5}{|c|}{ Uncooked } & \multicolumn{5}{|c|}{ Cooked } & \multicolumn{5}{|c|}{ Retrograded } \\
\hline & TAC & TFC & FRAP & ORAC & DPPH & TAC & TFC & FRAP & ORAC & DPPH & TAC & TFC & FRAP & ORAC & DPPH \\
\hline $\begin{array}{c}\text { TAC } \\
(n=56)\end{array}$ & & $0.74^{* *}$ & $0.84^{* *}$ & $0.73^{* *}$ & $0.70^{* *}$ & & $0.56^{* *}$ & $0.41^{* *}$ & $0.44^{* *}$ & $0.16^{*}$ & & $0.52^{* *}$ & $0.61^{* *}$ & $0.27^{*}$ & $0.31^{* *}$ \\
\hline $\begin{array}{c}\text { TPC } \\
(\mathrm{n}=84)\end{array}$ & $0.63^{* *}$ & $0.83^{* *}$ & $0.88^{* *}$ & $0.87^{* *}$ & $0.69^{* *}$ & $0.48^{* *}$ & $0.84^{* *}$ & $0.76^{* *}$ & $0.89^{* *}$ & $0.79^{* *}$ & $0.40^{* *}$ & $0.87^{* *}$ & $0.88^{* *}$ & $0.60^{* *}$ & $0.68^{* *}$ \\
\hline $\begin{array}{c}\text { TFC } \\
(\mathrm{n}=84)\end{array}$ & & & $0.97^{* *}$ & $0.82^{* *}$ & $0.75^{* * *}$ & & & $0.77^{* *}$ & $0.78^{* * *}$ & $0.84^{* *}$ & & & $0.97^{* *}$ & $0.58^{* * *}$ & $0.87^{* *}$ \\
\hline $\begin{array}{l}\text { FRAP } \\
(\mathrm{n}=84)\end{array}$ & & & & $0.90^{* *}$ & $0.76^{* *}$ & & & & $0.70^{* *}$ & $0.82^{* *}$ & & & & $0.56^{* *}$ & $0.89^{* * *}$ \\
\hline $\begin{array}{l}\text { ORAC } \\
(\mathrm{n}=84)\end{array}$ & & & & & $0.68^{* *}$ & & & & & $0.65^{* *}$ & & & & & $0.48^{* *}$ \\
\hline
\end{tabular}

$*,{ }^{* *}$ denote significant differences at $p \leq 0.05$ and 0.0001 respectively. TAC, total anthocyanin content; TPC, total phenolics content; TFC, total flavonoid content; FRAP, ferric reducing antioxidant power; ORAC, oxygen radical absorption capacity; DPPH, 2,2-Diphenyl-1-picrylhydrazyl radical scavenging capacity. 


\section{Discussion}

Epidemiological and experimental studies in cells, animal models of disease and human intervention trials demonstrate that polyphenolic compounds found in fruit and vegetables have the potential to enhance human health and even prevent, mitigate or treat many illnesses due to their antioxidant activities [4]. Many of the studies on phytochemical and antioxidant activities of coloured potatoes were conducted on raw potatoes [27] [28]. Although these types of studies produce valuable information, they do not document phytochemicals and antioxidant activities of potatoes that are consumed by humans. Besides maturity, genotype by environment interaction is reported to be a factor that influences the phytochemical composition [2] [5] [13] [15]. Processing conditions such as cooling, can influence the glycemic impact of cooked potatoes through retrogradation of starch polymers. It has been reported by low field nuclear magnetic resonance (LF-NMR) studies that retrogradation is more extensive in boiled potatoes after 24 - $48 \mathrm{~h}$ of cooling than after 1 - $2 \mathrm{~h}$ [29]. Since retrogradation of amylose is a rapid process often completed within $48 \mathrm{~h}$ [30], we chose $48 \mathrm{~h}$ for the cooling time in order to get the maximum effect of retrogradation. Considering the above mentioned factors, in the present study, fourteen early maturing potato varieties including two advanced selections with different skin and flesh colors were evaluated for their bioactive compounds such as TPC, TFC, and TAC, antioxidant activities and protein contents after processing. In general, the selections F09085 and F10090, and varieties, Purple Fiesta, Red Thumb and French Fingerlings registered the highest TPC, and TFC contents whereas highest TAC values were obtained in Purple Fiesta, F09085 and F10090. Among these varieties, Purple Fiesta has the darkest purple color skin and flesh, whereas F09085, F10090 with reddish purple skin and flesh, and Red Thumb have a deep red skin and flesh. French Fingerlings has a rose pink skin with a creamy yellow flesh with some splashes of pink color. Antioxidant activities as measured by FRAP, DPPH and ORAC were higher in F09085, F10090, Purple Fiesta, Red Thumb and French Fingerlings. It should be noted that the colored varieties either with flesh and skin or skin alone had higher TPC, TFC, TAC and higher FRAP, ORAC and DPPH values than yellow or white colored potatoes. Similar differences of higher phenolic contents and antioxidant activities were reported in uncooked yellow or white colored and pigmented potatoes [5] [31]-[33]. Higher correlations observed between TPC and antioxidant activities determined by FRAP, ORAC, DPPH and between FRAP, DPPH and ORAC values in uncooked samples in this study were also reported by other authors [5] [31]-[33].

Processing also affected TPC, TFC, TAC, FRAP and ORAC contents with the highest values often observed in retrograded samples followed by boiling and unprocessed samples. In general, the nutrient value of potatoes decreased after cooking [32]-[36]. However, it has been also reported that depending upon the variety and processing methods, TPC and antioxidant activities may either increase or decrease. For example, in potato clones such as CO97232-2R/Y, CO97215-2P/P and CO97227-2P/PW, the TPC contents increased after baking whereas values decreased following chipping compared to the unprocessed samples [35]. Also it has been reported that boiling of potato resulted in an increase and preservation of total anthocyanin contents as well as antioxidant content as measured by ORAC in red and purple-fleshed potato cultivars compared to raw tubers [15]. Our results also showed a similar trend of increased anthocyanin contents and antioxidant activities in boiled samples. Navarre et al. [37] have reported that processing of 3 varieties of new potatoes by various methods such as steaming, microwaving, boiling and baking increased the extractable phenolics and the TPC especially chlorogenic acids and TFC in all three cultivars after cooking. They also reported that the extent of increase was greatest after boiling. Their results also suggested that the increase in these nutrient contents after processing was consistent across all cultivars tested. The increase in TPC, TFC and TAC values could be attributable to greater extraction of these compounds after cooking due to the changes in cell matrix and the inactivation of the enzymes that degrade these components [13] [37]. It was also reported that the antioxidant capacity was increased by all the cooking methods compared to uncooked potatoes [35]. Ramírez-Anaya et al. [38] also reported significant increases in antioxidant activities of boiled compared to raw potatoes as measured by DPPH and FRAP.

Significant correlations were observed between TPC, TFC, TAC and FRAP and ORAC values in all the three processing methods in our study. Similar correlations between TPC, TAC and antioxidant activities as measured by ORAC, FRAP, DPPH have also been reported in potatoes by several authors [13] [32] [34] [35]. The lower correlation observed between TAC and ORAC, FRAP and DPPH values suggests that phenolics other than anthocyanins e.g. phenolic acids contribute more to the total antioxidant activities. TPC includes flavonoids, other phenolic acids and all compounds with phenolic features but the specific composition of these phenolic com- 
pounds can vary among different potato varieties, thus contributing differently to the antioxidant activity [33] [39]-[41].

Protein content of all varieties decreased by $19 \%-47 \%$ and $25 \%-47 \%$, respectively, in cooked and retrograded samples. It should be noted that in potato, water-soluble protein content varies from $49 \%-55 \%$ of total protein [42]. Hence it is suggested that the decrease in protein content after boiling may have resulted from leaching of the water-soluble proteins. Potato protein has a high biological value of 90 - 100 and is comparable to egg protein. Even though the protein content of potato is low, its high biological value and large consumption as a staple makes it a moderate nutritional source of proteins. It is also interesting to note that the colored varieties besides their high TPC, TFC, TAC and antioxidant capacities are also high in protein content. The loss of protein from these colored varieties was less (4\% - 25\%) compared to the white varieties which had a loss of $44 \%$ $47 \%$.

\section{Conclusion}

The present study identified F09085, F10090, French Fingerlings, Purple Fiesta, Red Thumb, Ciklamen and Norland as the nutritionally richest varieties among the 14 tested Ontario-grown potatoes according to the higher TPC, TFC, TAC contents, higher antioxidant activities and protein content. Potatoes were reported as the third leading source of dietary antioxidants in the North American diet after apples and oranges [43]. Potatoes could make a positive contribution to today's diet as consumers become more conscious and aware of the benefits of foods for health. Potatoes can be an excellent source of dietary antioxidants and energy and could be the basis for the development of functional foods.

\section{Acknowledgements}

The authors acknowledge the funding provided by the Ontario Ministry of Agriculture, Food and Rural Affairs, Ontario Potato Board and the Potato Cluster 11 of the AgriInnovation Program of Agriculture and Agri-Food Canada. Technical help from Brian Bryksa, Jiangyu Gao and Vanessa Currie of University of Guelph and Dr. Ronghua Liu of AAFC, Guelph was also greatly appreciated.

\section{References}

[1] Camire, M.E., Kubow, S. and Donnelly, D.J. (2009) Potatoes and Human Health. Critical Reviews in Food Science and Nutrition, 49, 823-840. http://dx.doi.org/10.1080/10408390903041996

[2] Andre, C.M., Ghislain, M., Bertin, P., Oufir, M., Herrera Mdle, R., Hoffmann, L., Hausman, J.F., Larondelle, Y. and Evers, D. (2007) Andean Potato Cultivars as a Source of Antioxidant and Mineral Micronutrients. Journal of Agricultural and Food Chemistry, 55, 366-378. http://dx.doi.org/10.1021/jf062740i

[3] Benavente-García, O. and Castillo, J. (2008) Update on Uses and Properties of Citrus Flavonoids: New Findings in Anticancer, Cardiovascular, and Anti-Inflammatory Activity. Agriculture and Food Chemistry, 56, 6185-205. http://dx.doi.org/10.1021/jf8006568

[4] Hurst, R.D. and Hurst, S.M. (2012) Fruits and Vegetables as Functional Foods for Exercise and Inflammation. In: Watson, R., Ed., Bioactive Food as Dietary Interventions for Arthritis and Related Inflammatory Diseases, ELSEVIER, Boston, 319-336.

[5] Hu, C., Tsao, R., Liu, R., Sullivan, J.A. and McDonald, R. (2012) Influence of Cultivar and Year on Phytochemical and Antioxidant Activity of Potato (Solanum tuberosum L.). Canadian Journal of Plant Science, 92, 485-493. http://dx.doi.org/10.4141/cjps2011-212

[6] Miedzianka, J., Peksa, A. and Aniołowska, M. (2012) Properties of Acetylated Potato Protein Preparations. Food Chemistry, 133, 1283-1291. http://dx.doi.org/10.1016/j.foodchem.2011.08.080

[7] Waglay, A., Karboune, S. and Alli, I. (2014) Potato Protein Isolates: Recovery and Characterization of Their Properties. Food Chemistry, 142, 373-382. http://dx.doi.org/10.1016/j.foodchem.2013.07.060

[8] Liu, Y.W., Han, C.H., J. Lee, M.H., Hsu, F.L. and Hou, W.C. (2003) Patatin, the Tuber Storage Protein of Potato (Solanum tuberosum L.), Exhibits Antioxidant Activity in Vitro. Agricultural and Food Chemistry, 51, 4389-4393.

[9] Lehesranta, S.J., Davies, H.V., Shepherd, L.V.T., Nunan, N., McNicol, J.W., Auriola, S., Koistinen, K.M., Suomalainen, S.S., Kokko, H.I. and Karenlampi, S.O. (2005) Comparison of Tuber Proteomes of Potato (Solanum sp.) Varieties, Landraces and Genetically Modified Lines. Plant Physiology, 138, 1690-1699.

http://dx.doi.org/10.1104/pp.105.060152 
[10] Lehesranta, S.J., Davies, H.V., Shepherd, L.V.T., Koistinen, K.M., Massat, N., Nunan, N., McNicol, J.W. and Karenlampi, S.O. (2006) Proteomic Analysis of the Potato Tuber Life Cycle. Proteomics, 6, 6042-6052. http://dx.doi.org/10.1002/pmic.200600383

[11] Lehesranta, S.J., Koistinen, K.M., Massat, N., Davies, H.V., Shepherd, L.V.T., McNicol, J.W., Cakmak, I., Cooper, J., Luck, L., Karenlampi, S.O. and Leifert, C. (2007) Effects of Agricultural Production Systems and Their Components on Protein Profiles of Potato Tubers. Proteomics, 7, 597-604. http://dx.doi.org/10.1002/pmic.200600889

[12] Peksa, A., Kita, A., Kułakowska, K., Aniołowska, M., Hamouz, K. and Nems, A. (2013) The Quality of Protein of Coloured Fleshed Potatoes. Food Chemistry, 141, 2960-2966. http://dx.doi.org/10.1016/j.foodchem.2013.05.125

[13] Ezekiel, R., Singh, N., Sharma, S. and Kaur, A. (2013) Beneficial Phytochemicals in Potato-A Review. Food Research International, 50, 487-496. http://dx.doi.org/10.1016/j.foodres.2011.04.025

[14] Lachman, J., Hamouz, K., Musilová, J., Hejtmánková, K., Kotíková, Z., Pazderu, K., Domkár`ová, J., Pivec, V. and Cimr, J. (2013) Effect of Peeling and Three Cooking Methods on the Content of Selected Phytochemicals in Potato Tubers with Various Colour of Flesh. Food Chemistry, 138, 1189-1197. http://dx.doi.org/10.1016/j.foodchem.2012.11.114

[15] Brown, C.R., Durst, R.W., Wrolstad, R. and De Jong, W. (2008) Variability of Phytonutrient Content of Potato in Relation to Growing Location and Cooking Method. Potato Research, 51, 259-270. http://dx.doi.org/10.1007/s11540-008-9115-0

[16] Food and Agriculture Organization (2008) Global Potato Production Statistics. World Health Organization. http://www.potato2008.org/en/world/index.html

[17] Goyer, A. and Navarre, D.A. (2009) Folate Is Higher in Developmentally Younger Potato Tubers. Journal of the Science of Food and Agriculture, 89, 579-583. http://dx.doi.org/10.1002/jsfa.3470

[18] Zhu, F., Cai, Y.Z., Ke, J. and Corke, H. (2010) Composition of Phenolic Compounds, Amino Acids and Reducing Sugars in Commercial Potato Varieties and Their Effects on Acrylamide Formation. Journal of Science, Food and Agriculture, 90, 2254-2262. http://dx.doi.org/10.1002/jsfa.4079

[19] Waterhouse, A.L. (2001) Determination of Total Phenolics. In: Wrolstad, R.E., Ed., Current Protocols in Food Analytical Chemistry, Wiley, Hoboken, 11.1.1-11.1.8.

[20] Zou, Y., Chang, S.K.C., Gu, Y. and Qian, S.Y. (2011) Antioxidant Activity and Phenolic Compositions of Lentil Extract and Its Fractions. Journal of Agricultural and Food Chemistry, 59, 2268-2276. http://dx.doi.org/10.1021/jf104640k

[21] Fuleki, T. and Francis, F.J. (1968) Quantitative Methods for Anthocyanins 1. Extraction and Determination of Total Anthocyanins in Cranberry Juice. Journal of Food Science, 33, 72-77. http://dx.doi.org/10.1111/j.1365-2621.1968.tb00887.x

[22] Yamaguchi, T., Takamura, H., Matoba, T. and Terao, J. (1998) HPLC Method for Evaluation of the Free RadicalScavenging Activity of Food by Using 1, 1-Diphenyl-2-Picrylhydrazil. Bioscience, Biotechnology and Biochemistry, 62, 1201-1204. http://dx.doi.org/10.1271/bbb.62.1201

[23] Benzie, I.F.F. and Strain, J.J. (1996) The Ferric Reducing Ability of Plasma (FRAP) as a Measure of "Antioxidant Power”: The FRAP Assay. Analytical Biochemistry, 239, 70-76. http://dx.doi.org/10.1006/abio.1996.0292

[24] Tsao, R., Yang, R., Xie, S., Sockovie, E. and Khanizadeh, S. (2005) Which Polyphenolic Compounds Contribute to the Total Antioxidant Activities of Apple? Journal of Agricultural and Food Chemistry, 53, 4989-4995. http://dx.doi.org/10.1021/jf048289h

[25] Huang, D., Ou, B., Hampsch-Woodill, M., Flanagan, J.A. and Prior, R.L. (2002) High-Throughput Assay of Oxygen Radical Absorbance Capacity (ORAC) Using a Multichannel Liquid Handling System Coupled with a Microplate Fluorescence Reader in 96-Well Format. Journal of Agricultural and Food Chemistry, 50, 4437-4444. http://dx.doi.org/10.1021/jf0201529

[26] Barta, J. and Bartova, V. (2008) Patatin, the Major Protein of Potato (Solanum tuberosum L.) Tubers, and Its Occurrence as Genotype Effect: Processing versus Table Potatoes. Czech Journal of Food Sciences, 26, 347-359.

[27] Malmberg, A.G. and Theander, O. (1985) Determination of Chlorogenic Acid in Potato Tubers. Journal of Agricultural and Food Chemistry, 33, 549-551.

[28] Hale, A.L. (2003) Screening Potato Genotypes for Antioxidant Activity, Identification of the Responsible Compounds, and Differentiating Russet Norkotah Strains Using AFLP and Microsatellite Marker Analysis. PhD Thesis, Texas A\&M University, College Station, 255.

[29] Micklander, E., Thybo, A.K. and van den Berg, F. (2008) Changes Occurring in Potatoes during Cooking and Reheating as Affected by Salting and Cool or Frozen Storage-A LF-NMR Study. LWT_Food Science and Technology, 41, 1710-1719. http://dx.doi.org/10.1016/j.lwt.2007.10.015

[30] Miles, M.J., Morris, V.J., Orford, P.D. and Ring, S.G. (1985) The Roles of Amylose and Amylopectin in the Gelation 
and Retrogradation of Starch. Carbohydrate Research, 135, 271-281. http://dx.doi.org/10.1016/s0008-6215(00)90778-X

[31] Li, H., Deng, Z., Zhu, H., Hu, C., Liu, R., Young, J.C. and Tsao, R. (2012) Highly Pigmented Vegetables. Anthocyanin Compositions and Their Role in Antioxidant Activities. Food Research International, 46, 250-259. http://dx.doi.org/10.1016/j.foodres.2011.12.014

[32] Lachman, J., Hamouz, K., Sulc, M., Orsak, M. and Dvorak, P. (2008) Differences in Phenolic Content and Antioxidant Activity in Yellow and Purple-Fleshed Potatoes. Plant Soil Environment, 54, 1-6.

[33] Im, H.W., Suh, B.S., Lee, S.U., Kozukue, N., Ohnisi-Kameyama, M., Levin, C.E. and Friedman, M. (2008) Analysis of Phenolic Compounds by High-Performance Liquid Chromatography and Liquid Chromatography/Mass Spectrometry in Potato Plant Flowers, Leaves, Stems, and Tubers and in Home-Processed Potatoes. Journal of Agricultural and Food Chemistry, 56, 3341-3349. http://dx.doi.org/10.1021/jf073476b

[34] Tudela, J.A., Cantos, E., Espin, J.C., Tomas-Barberan, F.A. and Gil, M.I. (2002) Induction of Antioxidant Flavonol Biosynthesis in Fresh-Cut Potatoes. Effect of Domestic Cooking. Journal of Agricultural and Food Chemistry, 50, 5925-5931. http://dx.doi.org/10.1021/jf020330y

[35] Santos, C.S.P., Cunha, S. and Casal, S. (2015) Bioactive Components in Potatoes as Influenced by Thermal Processing. In: Preedy, V.R., Ed., Processing and Impact on Active Components in Food, Academic Press, Elsevier Inc., London, 111-119. http://dx.doi.org/10.1016/b978-0-12-404699-3.00014-7

[36] Madiwale, G.P., Reddivari, L., Stone, M., Holm, D.G. and Vanamala, J. (2012) Combined Effects of Storage and Processing on the Bioactive Compounds and Pro-Apoptotic Properties of Color-Fleshed Potatoes in Human Colon Cancer Cells. Journal of Agricultural and Food Chemistry, 60, 11088-11096. http://dx.doi.org/10.1021/jf303528p

[37] Navarre, D.A., Shakya, R., Holden, J. and Kumar, S. (2010) The Effect of Different Cooking Methods on Phenolics and Vitamin C in Developmentally Young Potato Tubers. American Journal of Potato Research, 87, 350-359. http://dx.doi.org/10.1007/s12230-010-9141-8

[38] Ramírez-Anaya, J.P., Samaniego-Sánchez, C., Castañeda-Saucedo, M.C., Villalón-Mir, M. and de la Serrana, H.L.G. (2015) Phenols and the Antioxidant Capacity of Mediterranean Vegetables Prepared with Extra Virgin Olive Oil Using Different Domestic Cooking Techniques. Food Chemistry, 188, 430-438. http://dx.doi.org/10.1016/j.foodchem.2015.04.124

[39] Brown, C.R. (2005) Antioxidants in Potato. American Journal of Potato Research, 82, 163-172. http://dx.doi.org/10.1007/BF02853654

[40] Tsao, R. and McCallum, J. (2010) Chemistry of Flavonoids, In: de la Rosa, L.A., Alvarez-Parrilla, E. and GonzalezAguilar, G.A., Eds., Fruit and Vegetable Phytochemicals, WILEY-Blackwell, Ames, 131-153.

[41] Ozgen, M., Scheerens, J.C., Reese, R.N. and Miller, R.A. (2010) Total Phenolic, Anthocyanin Contents and Antioxidant Capacity of Selected Elderberry Accessions. Pharmacognosy Magazine, 6, 198-203. http://dx.doi.org/10.4103/0973-1296.66936

[42] Løkra, S., Helland, M.H., Claussen, I.C., Strætkvern, K.O. and Egelandsdal, B. (2008) Chemical Characterization and Functional Properties of a Potato Protein Concentrate Prepared by Large-Scale Expanded Bed Adsorption Chromatography. LWT_Food Science and Technology, 41, 1089-1099. http://dx.doi.org/10.1016/j.lwt.2007.07.006

[43] Chun, O.K., Kim, D.O., Smith, N., Schroeder, D., Han, J.T. and Lee, C.Y. (2005) Daily Consumption of Phenolics and Total Antioxidant Capacity from Fruit and Vegetables in the American Diet. Journal of Science, Food and Agriculture, 85, 1715-1724. http://dx.doi.org/10.1002/jsfa.2176 